\title{
Release from optimal compressive force suppresses osteoclast differentiation
}

\author{
MASAAKI IKEDA ${ }^{1,2}$, YOSHITAKA YOSHIMURA ${ }^{2}$, TAKASHI KIKUIRI ${ }^{3}$, MINO MATSUNO ${ }^{2}$, \\ TOMOKAZU HASEGAWA ${ }^{4}$, KUMU FUKUSHIMA ${ }^{1}$, TAKAKO HAYAKAWA ${ }^{1}$, \\ HAJIME MINAMIKAWA ${ }^{2}$, KUNIAKI SUZUKI ${ }^{2}$ and JUNICHIRO IIDA ${ }^{1}$ \\ Departments of ${ }^{1}$ Orthodontics, ${ }^{2}$ Molecular Cell Pharmacology and ${ }^{3}$ Pediatric Dentistry, \\ Hokkaido University Graduate School of Dental Medicine, Sapporo, Hokkaido 060-8586; ${ }^{4}$ Department of Pediatric Dentistry, \\ Faculty of Dentistry, Tokushima University, Tokushima 770-8504, Japan
}

Received September 3, 2015; Accepted September 8, 2016

DOI: $10.3892 / \mathrm{mmr} .2016 .5801$

\begin{abstract}
Bone remodeling is an important factor in orthodontic tooth movement. During orthodontic treatment, osteoclasts are subjected to various mechanical stimuli, and this promotes or inhibits osteoclast differentiation and fusion. It has been previously reported that the release from tensile force induces osteoclast differentiation. However, little is known about how release from compressive force affects osteoclasts. The present study investigated the effects of release from compressive force on osteoclasts. The number of tartrate-resistant acid phosphatase (TRAP)-positive multinucleated osteoclasts derived from RAW264.7 cells was counted, and gene expression associated with osteoclast differentiation and fusion in response to release from compressive force was evaluated by reverse transcription-quantitative polymerase chain reaction. Osteoclast number was increased by optimal compressive force application. On release from this force, osteoclast differentiation and fusion were suppressed. mRNA expression of NFATc1 was inhibited for $6 \mathrm{~h}$ subsequent to release from compressive force. mRNA expression of the other osteoclast-specific genes, TRAP, RANK, matrix metalloproteinase-9, cathepsin-K, chloride channel 7, ATPase $\mathrm{H}^{+}$transporting vacuolar proton pump member I, dendritic cell-specific transmembrane protein and osteoclast stimulatory transmembrane protein (OC-STAMP) was significantly inhibited at $3 \mathrm{~h}$ following release from compressive force compared with control cells. These findings suggest that release from optimal compressive force suppresses osteoclast
\end{abstract}

Correspondence to: Dr Yoshitaka Yoshimura, Department of Molecular Cell Pharmacology, Hokkaido University Graduate School of Dental Medicine, Kita 13 Nishi 7, Kita-ku, Sapporo, Hokkaido 060-8586, Japan

E-mail: yoshi@den.hokudai.ac.jp

Key words: release from compressive force, compressive force, mechanical stress, osteoclast, osteoclastogenesis differentiation and fusion, which may be important for developing orthodontic treatments.

\section{Introduction}

Bone remodeling is a balance between bone resorption by osteoclasts and bone formation by osteoblasts (1). When this balance tips toward excess resorption, the risk of osteoporosis is increased, whereas osteoclast dysfunction increases the risk of osteopetrosis (2). Thus, osteoclasts have an important function in bone homeostasis. In orthodontic treatment, osteoclasts are also important for tooth movement $(3,4)$. Promotion of osteoclast differentiation accelerates bone resorption. By contrast, inhibiting osteoclast differentiation accelerates formation. Orthodontic force consists of tensile and compressive force. On the pressure side, osteoclasts are subjected to compressive force. By contrast, on the tension side, osteoclasts are subjected to tensile force. During orthodontic treatment, numerous stimuli are applied to osteoclasts; certain signals promote osteoclast differentiation, whereas others inhibit osteoclast differentiation (3).

Osteoclasts are multinucleated, bone-resorbing cells that are differentiated from the monocyte/macrophage hematopoietic lineage (5). Receptor activator of nuclear factor- $\kappa \mathrm{B}$ (RANK)-ligand (RANKL) is an essential factor for osteoclast differentiation. RANKL binding to RANK induces expression of nuclear factor of activated T cells 1 (NFATc1). NFATc1 is the master transcription factor for osteoclast differentiation (6). An increase in the expression of NFATc1 promotes transcription of various osteoclast-specific genes. Numerous studies have previously reported that stimulation of osteoclasts leads to secretion of cytokines associated with bone resorption and formation (7-10).

In a previous study, various types of mechanical stimuli were applied to osteoclasts, and it was reported that these were influential factors in bone remodeling. Mechanical stimuli include tensile force $(8,9,11-14)$, compressive force $(7,10,15-17)$, hydrostatic pressure (18), sheer stress $(19,20)$, rotative stress (21) and others $(22,23)$. Stimulation with tensile force using a Flexercell tension system suppresses osteoclast differentiation and fusion. The number of osteoclasts increases 
rapidly after the release of tensile force. Additionally, optimal compressive force induces osteoclast differentiation (9). In this experiment, osteoclasts on slips are reversed and placed on collagen gel layers, and compressive force was adjusted using weights. Optimal compressive force is defined as the weight that induces the largest increase in the number of osteoclasts, and is $280 \mathrm{mg} / \mathrm{cm}^{2}$ according to Hayakawa et al (10). Thus, the present study investigated the effects of release from optimal compressive force on osteoclasts.

\section{Materials and methods}

Cell culture. The current study used the murine monocyte/macrophage cell line RAW264.7 cells (TIB-71 ${ }^{\mathrm{TM}}$; American Type Culture Collection, Manassas, VA, USA) as osteoclast precursors. Cells were maintained in Dulbecco's modified Eagle's medium (Wako Pure Chemical Industries, Ltd., Osaka, Japan) containing 10\% heat-inactivated fetal bovine serum (FBS; Invitrogen; Thermo Fisher Scientific, Inc., Waltham, MA, USA) and $66.7 \mu \mathrm{g} / \mathrm{ml}$ kanamycin sulfate (Meiji Seika Kaisha, Ltd., Tokyo, Japan) at $37^{\circ} \mathrm{C}$ in $5 \% \mathrm{CO}_{2}$ in humidified air. Cells were seeded in 100-mm standard dishes (Corning Incorporated, Corning, NY, USA) and incubated overnight. Subsequently, for osteoclast differentiation, RAW cells $\left(1 \times 10^{4}\right.$ cells/well $)$ were transferred into 24 -well culture plates (Corning Incorporated) and cultured on 12-mm diameter glass cover slips (Fisher Microscope Cover Glass; Thermo Fisher Scientific, Inc.) placed on the 24-well culture plate, in $\alpha$-minimum essential medium ( $\alpha$-MEM; Wako Pure Chemical Industries, Ltd.) supplemented with $10 \%$ heat-inactivated FBS, 2 mM L-alanyl-L-glutamine (Wako Pure Chemical Industries, Ltd.), $284 \mu \mathrm{M}$ L-ascorbic acid phosphate magnesium salt n-hydrate (Wako Pure Chemical Industries, Ltd.), $66.7 \mu \mathrm{g} / \mathrm{ml}$ kanamycin sulfate and $50 \mathrm{ng} / \mathrm{ml}$ RANKL (Oriental Yeast Co., Ltd., Tokyo Japan) at $37^{\circ} \mathrm{C}$ under $5 \% \mathrm{CO}_{2}$ in humidified air. Medium was changed every other day.

Preparation of collagen gels. The collagen mixture comprised acid-soluble collagen solution (Cellmatrix; Nitta Gelatin NA Inc., Morrisville, NC, USA) mixed with 10-fold concentrated $\alpha$-MEM and reconstruction buffer $\left(2.2 \mathrm{~g} \mathrm{NaHCO}_{3}+4.77 \mathrm{~g}\right.$ HEPES in $100 \mathrm{ml} 0.05 \mathrm{~N} \mathrm{NaOH}$; Nitta Gelatin NA Inc.) at a volume ratio of $8: 1: 1$, and supplemented with $10 \%$ heat-inactivated FBS (Invitrogen; Thermo Fisher Scientific, Inc.), $284 \mu \mathrm{M}$ L-ascorbic acid 2-phosphate (Sigma-Aldrich; Merck Millipore, Darmstadt, Germany) and $2 \mathrm{mM}$ L-alanyl-L-glutamine (Wako Pure Chemical Industries, Ltd.) at below $4^{\circ} \mathrm{C}$. This collagen mixture was placed into 24 -well culture plates at a volume of $500 \mu \mathrm{l} /$ well, and was solidified in a $\mathrm{CO}_{2}$ incubator at $37^{\circ} \mathrm{C}$ for $30 \mathrm{~min}$. After gelation, $1 \mathrm{ml} /$ well culture medium supplemented with $50 \mathrm{ng} / \mathrm{ml}$ RANKL was overlaid in each well.

Application of compressive forces. RAW264.7 cells $\left(1 \times 10^{4}\right.$ cells/well) were cultured for 3 days on thin glass slips (diameter, $12 \mathrm{~mm}$; thickness, $0.1 \mathrm{~mm}$ ). Osteoclasts on slips were then inverted and placed on collagen gel layers that were prepared in other 24-well culture plates. Compressive force was adjusted by placing a weight on a slip (10). Seven layered slips ( 40 mg/slip) were used as a weight. Cells were subjected to $280 \mathrm{mg} / \mathrm{cm}^{2}$ of compressive force for $24 \mathrm{~h}$, whereas control cells were inverted and placed on collagen gel layers without weights.

Release from compressive forces. After cells had been compressed and incubated for $24 \mathrm{~h}$, weights were removed, and cells on slips were inverted. Subsequently, cells were incubated for $24 \mathrm{~h}$.

Tartrate-resistant acid phosphatase (TRAP) staining. After cells were cultured for a 2, 3, 4, 5 or 6 days, and fixed with $10 \%$ neutral formalin for $30 \mathrm{~min}$ at room temperature, they were washed with distilled water and treated with TRAP staining solution (pH 5.0) supplemented with Fast Red Violet LB Salt (Sigma Aldrich; Merck Millipore) (24). TRAP staining solution contained acetate buffer (pH 5.0; Sigma-Aldrich; Merck Millipore), naphthol AS-MX phosphate (Sigma-Aldrich; Merck Millipore) as a substrate, red violet LB (Sigma-Aldrich; Merck Millipore) as a stain in the presence of $50 \mathrm{mM}$ sodium tartrate (Wako Pure Chemical Industries, Ltd.). TRAP-positive cells with $\geq 2$ nuclei were counted under the microscope as osteoclasts. TRAP-positive cells with 2-7 nuclei were considered to be small osteoclasts, and those with $\geq 8$ nuclei to be large osteoclasts $(8,9)$.

Reverse transcription-quantitative polymerase chain reaction (RT-qPCR). Cells were incubated for 1,3, 6, 12 and $24 \mathrm{~h}$ in 24-well culture plates, after compression for $24 \mathrm{~h}$. Total RNA was isolated from cultured cells under each set of conditions using TRIzol (Invitrogen; Thermo Fisher Scientific, Inc.) (25) according to the manufacturer's instructions, and aliquots containing equal amounts of mRNA were subjected to RT-qPCR. First-strand cDNA synthesis was performed using $1 \mu \mathrm{g}$ total RNA, 25 pmol oligo dT (Toyobo Co., Ltd., Osaka, Japan), 1 mM dNTP (Toyobo Co., Ltd.), 100 U ReverTra Ace ${ }^{\circledR}$ (Toyobo Co., Ltd.), 20 U RNase inhibitor (Toyobo Co., Ltd.) and $4 \mu 15 \mathrm{X}$ reaction mixture (Toyobo Co., Ltd.) in $20 \mu \mathrm{l}$ with annealing at $30^{\circ} \mathrm{C}$ for $10 \mathrm{~min}$, enzyme reaction at $42^{\circ} \mathrm{C}$ for $20 \mathrm{~min}$, denaturation at $99^{\circ} \mathrm{C}$ for $5 \mathrm{~min}$ and cooling at $4^{\circ} \mathrm{C}$. qPCR was performed using the ABI Prism 7300 sequence detection system (Applied Biosystems; Thermo Fisher Scientific, Inc.). The reactions were incubated at $50^{\circ} \mathrm{C}$ for $2 \mathrm{~min}$ and $95^{\circ} \mathrm{C} 10 \mathrm{~min}$, followed by 40 cycles of $95^{\circ} \mathrm{C}$ for $15 \mathrm{sec}$ and annealing at $60^{\circ} \mathrm{C}$ for $1 \mathrm{~min}$. The following specific TaqMan probes (Applied Biosystems; Thermo Fisher Scientific, Inc.) for osteoclast-associated genes were used: NFATc1 (ID no. Mm00479445_ml), TRAP (ID no. Mm00475698_ ml), matrix metalloproteinase-9 (MMP-9; ID no.Mm00432271_ml), RANK(ID no.Mm-00437135_ml), osteoclast stimulatory trans membrane protein (OC-STAMP; ID no. Mm00512445_ml), dendritic cell specific trans membrane protein (DC-STAMP; ID no. Mm01168058_ml), cathepsin-K (Cath-K; ID no. Mm00484036_ml), chloride channel 7 (ClC-7; ID no. Mm00442400_ml) and ATPase $\mathrm{H}^{+}$transporting vacuolar proton pump member I (ATP6i; ID no. Mm00469395_gl). Levels of mRNA expression were calculated and standardized against the level of glyceraldehyde 3-phosphate dehydrogenase (GAPDH; ID no. Mm99999915_gl) mRNA. Following each PCR run, data were analyzed by the system and amplification plots 
A

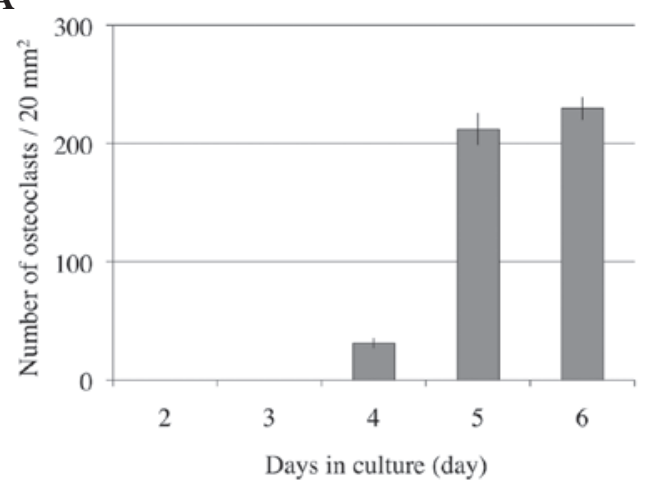

B

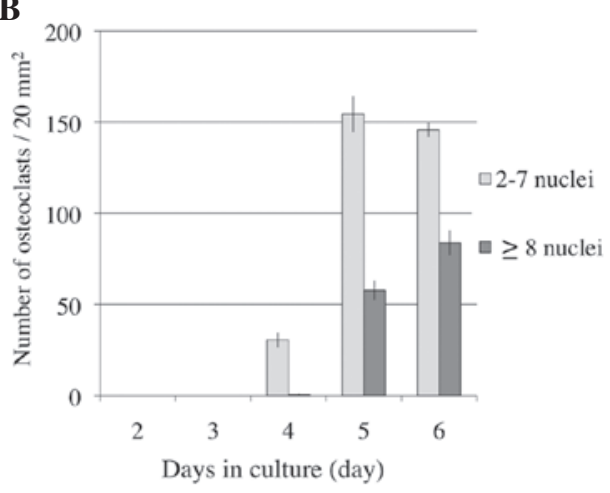

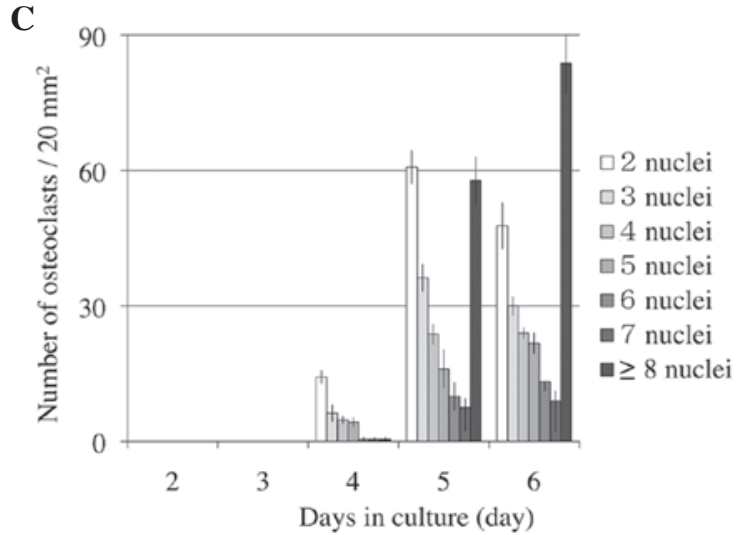

Figure 1. Number of osteoclasts on each day of culture. (A) RAW cells were cultured in 24-well plates. After various durations in culture, the number of osteoclasts was counted. (B) Small (2-7 nuclei) and large ( $\geq 8$ nuclei) osteoclasts were counted. (C) Osteoclasts with various numbers of nuclei were counted. Results are presented as the mean \pm standard deviation $(\mathrm{n}=4)$.

were obtained. qPCR results were calculated using the $2^{-\Delta \Delta C q}$ method (26).

Statistical analysis. Values represent the mean \pm standard deviation. Comparisons between two groups were analyzed by 2-tailed unpaired Student's $t$ test. $\mathrm{P}<0.05$ was considered to indicate a statistically significant difference.

\section{Results}

Number of osteoclasts on various culture days. In order to determine when osteoclast differentiation and fusion were activated, the number of osteoclasts and the nuclei in osteoclasts were observed for 6 days. Osteoclasts induced from RAW264.7 cells were cultured with $50 \mathrm{ng} / \mathrm{ml}$ RANKL on 24-well culture plates for 6 days. The number of osteoclasts increased rapidly on day 5, and marginally on day 6 (Fig. 1A). Small osteoclasts (2-7 nuclei) did not increase in number, but large osteoclasts ( $\geq 8$ nuclei) increased on day 6 (Fig. 1B). Even in small osteoclasts, osteoclasts with 2-3 nuclei decreased, however osteoclasts with 4-7 nuclei did not increase (Fig. 1C).

Number of osteoclasts increases in response to compressive force during osteoclast differentiation. In order to determine whether compressive force induced osteoclast differentiation, the number of TRAP-positive multinucleated osteoclasts was assessed by TRAP staining. Compressive force was applied for $24 \mathrm{~h}$, whereas control cells were incubated under the same conditions, but without compressive force. TRAP-positive multinucleated cells with $>2$ nuclei were counted under the microscope. The number of osteoclasts with compressive force was increased significantly compared with the control group ( $\mathrm{P}=0.03$; Fig. $2 \mathrm{~A}$ ). Furthermore, the number of small osteoclasts (2-7 nuclei) and large osteoclasts ( $\geq 8$ nuclei) with compressive force was significantly increased compared with the control groups $(\mathrm{P}=0.04$ and $\mathrm{P}=0.03$, respectively; Fig. 2B).

Number of osteoclasts following release from compressive force. The effect of the release from compressive force on osteoclasts was also examined. Following release from compressive force, osteoclast differentiation and fusion were decreased in comparison with the control groups. The number of osteoclasts release from compressive force increased 1.7 fold. However, the number in the control groups increased by 2.4 fold. The total number of osteoclasts in the control groups was significantly greater than the cells released from compressive force $(\mathrm{P}=0.02$; Fig. $3 \mathrm{~A})$. The number of small osteoclasts (2-7 nuclei) and large osteoclasts ( $\geq 8$ nuclei) in the control group was increased compared with the cells released from compressive force $(\mathrm{P}=0.04$ and $\mathrm{P}=0.03$, respectively; Fig. 3B).

Effects of release from compressive force on the expression of osteoclast differentiation genes. How the expression of osteoclast differentiation genes was altered by release from compressive force was investigated using RT-qPCR analysis 
A

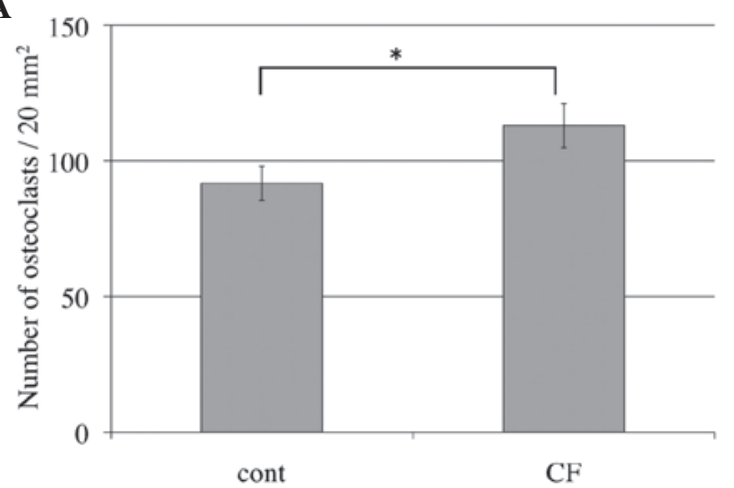

B

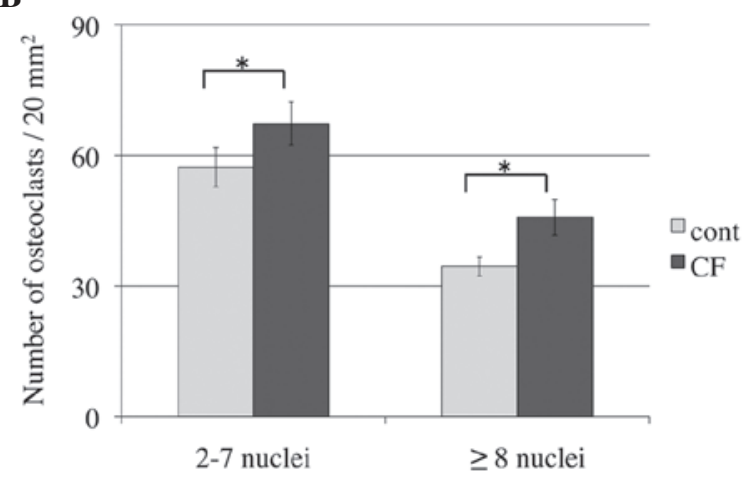

Figure 2. Effects of optimal CF for $24 \mathrm{~h}$ on osteoclastogenesis. The number of osteoclasts is counted at day 4 of culture. (A) Total osteoclasts were counted. (B) Small (2-7 nuclei) and large ( $\geq 8$ nuclei) osteoclasts were counted. Results are presented as the mean \pm standard deviation $(n=4)$. "P<0.05, comparison indicated by brackets. cont, control; CF, compressive force.

A

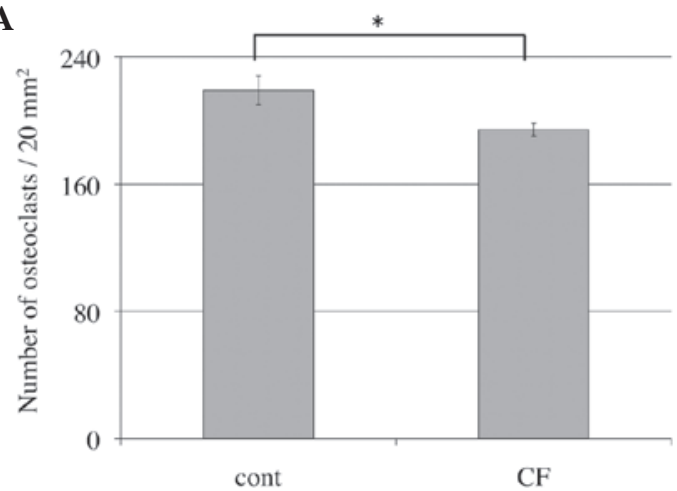

B

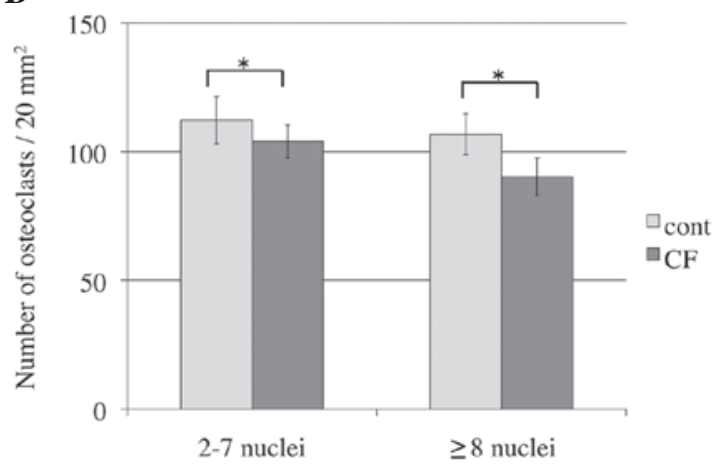

Figure 3. Effects of release from optimal CF on osteoclastogenesis. The number of osteoclasts is counted at day 5 of culture. (A) Total osteoclasts were counted. (B) Small (2-7 nuclei) and large ( $\geq 8$ nuclei) osteoclasts were counted. Results are presented as the mean \pm standard deviation ( $=4$ ). $\mathrm{P}<0.05$, comparison indicated by brackets. cont, control; $\mathrm{CF}$, compressive force.

for osteoclast-specific genes (NFATc1, TRAP, RANK, MMP-9, Cath-K, ClC7 and ATP6i) and fusion-associated factors (DC-STAMP and OC-STAMP). Analysis demonstrated that NFATc1 mRNA levels in the control groups were increased at $0,1,3$ and $6 \mathrm{~h}$ compared with the cells released from compressive force $(\mathrm{P}=0.0003, \mathrm{P}=0.003, \mathrm{P}=0.0005$ and $\mathrm{P}=0.05$, respectively). However, TRAP, RANK, MMP-9, Cath-K, ClC7, ATP6i, DC-STAMP, OC-STAMP mRNA levels peaked at $3 \mathrm{~h}$ in control groups; and were significantly increased compared with the cells that had been released from compressive force (all $\mathrm{P}<0.01$; Fig. 4).

\section{Discussion}

Orthodontic tooth movement is achieved by the remodeling of periodontal ligament and alveolar bone in response to mechanical pressure and tension $(3,4)$. During tooth movement, osteoclasts remove bone on the pressure side and osteoblasts create new bone on the tension side of the tooth. Following the release of orthodontic force from teeth, orthodontic relapse occurs. Orthodontic relapse can be defined as the tendency for teeth to return to their pre-treatment position. This is considered to be due to gingival fibers and unbalanced lip-tongue force (27). However, effects of release from orthodontic force on osteoclasts are unknown.
In a previous study, osteoclasts were subjected to various types of force in vitro. During orthodontic treatment, osteoclasts are subjected to compressive force on the pressure side, and tensile force on the tension side. The number of osteoclasts was observed to decrease following the application of tensile force using a Flexercell tension system (9). Osteoclast differentiation was upregulated subsequent to release from tensile force (8). By contrast, optimal compressive force induced osteoclast differentiation and fusion (10). Thus, the aim of the present study was to investigate the effects of release from compressive force on the pressure side of tooth movement in vitro.

In order to investigate the effects of release from optimal compressive force on osteoclast differentiation, the number of TRAP-positive cells was counted and the expression of NFATc1, TRAP, MMP-9, Cath-K, ClC7, ATP6i, DC-STAMP and OC-STAMP mRNA was examined.

The results presented in Fig. 1A suggest that osteoclastogenesis advances rapidly after 4-5 days. Osteoclastogenesis continued to increase up to day 6 , therefore, indicating that the most appropriate time to apply compressive force was at days 4-5 and to release compressive force at day 5 .

As described above, the optimal compressive force was defined as $280 \mathrm{mg} / \mathrm{cm}^{2}$, which induced the greatest increase in osteoclasts in a previous experiment using collagen gels (10). 
A

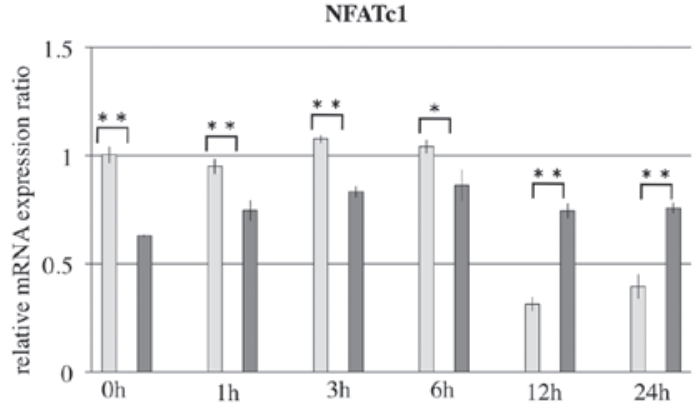

C

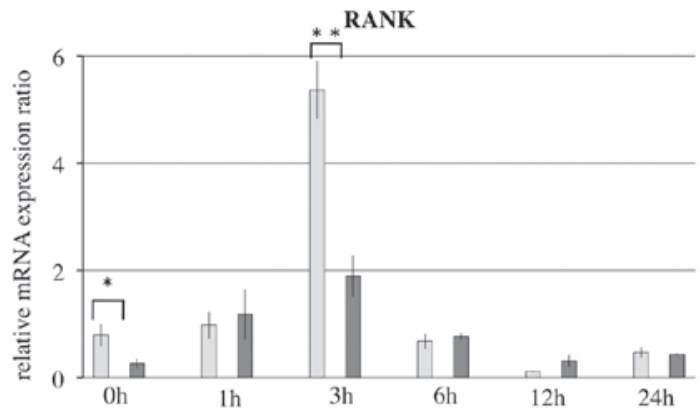

$\mathbf{E}$

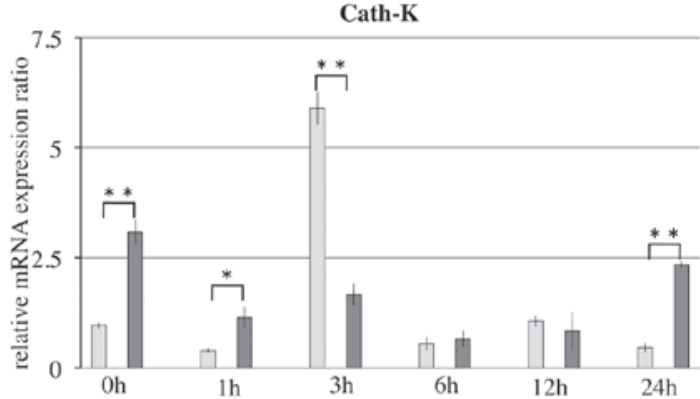

G

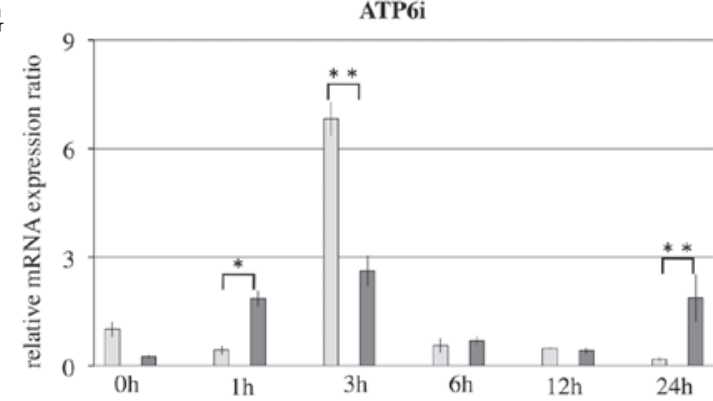

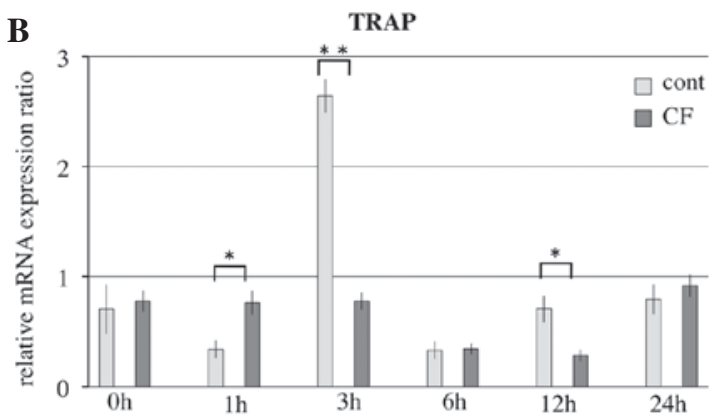
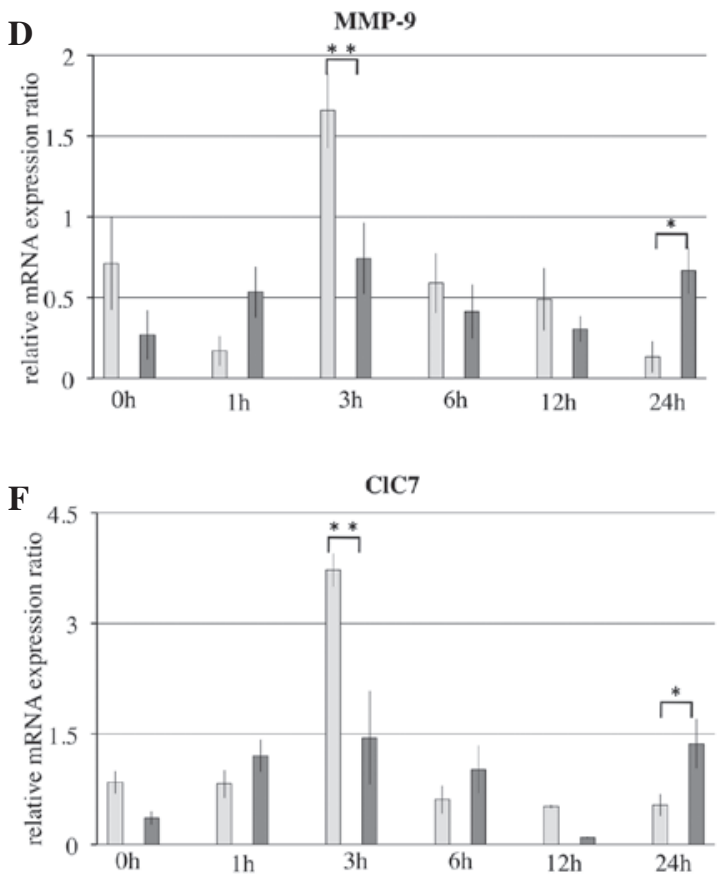

H

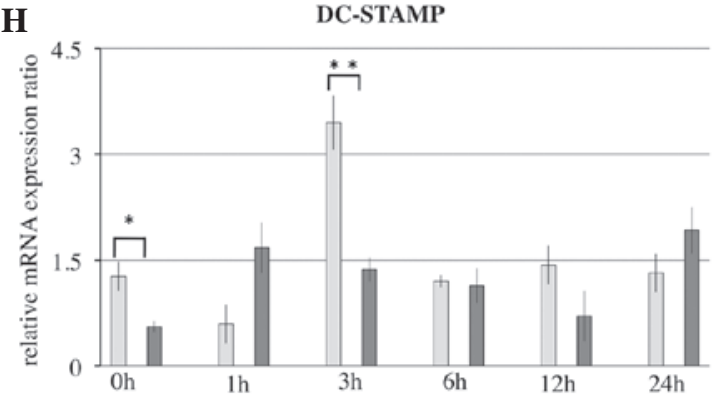

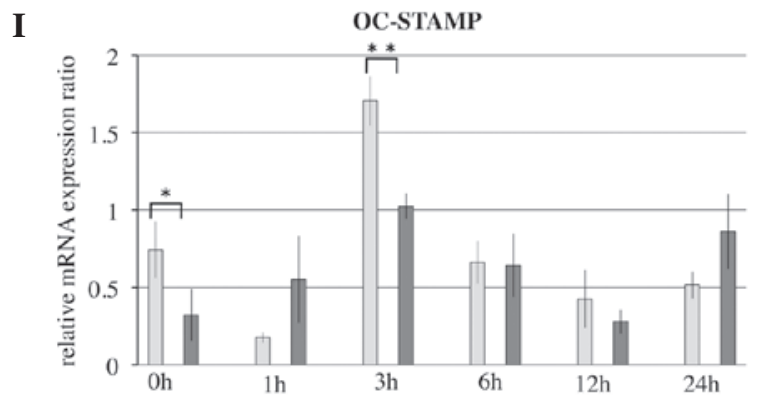

Figure 4. Effects of release from optimal CF on mRNA levels of osteoclast-associated genes for 1-24 h. mRNA levels of osteoclast-associated genes (A) NFATc1 (B) TRAP (C) RANK (D) MMP-9 (E) Cath-K (F) ClC7 (G) ATP6i (H) DC-STAMP and (I) OC-STAMP were evaluated by reverse transcription-quantitative polymerase reaction. Results are presented as the mean \pm standard deviation $(n=4)$. ${ }^{*} \mathrm{P}<0.05,{ }^{* * *} \mathrm{P}<0.01$, comparison indicated by brackets. cont, control; $\mathrm{CF}$, compressive force; NFATc1, nuclear factor of activated T cells 1; TRAP, tartrate-resistant acid phosphatase; RANK, receptor activator of nuclear factor- $\mathrm{kB}$; MMP-9, matrix metalloproteinase-9; Cath-K, cathepsin-K; ClC7, chloride channel 7; ATP6i, ATPase $\mathrm{H}^{+}$transporting vacuolar proton pump member I; DC-STAMP, dendritic cell-specific transmembrane protein; OC-STAMP, osteoclast stimulatory transmembrane protein. 
Optimal compressive force had been applied to osteoclasts for $24 \mathrm{~h}$; the number of TRAP-positive multinucleated osteoclasts was increased in the compressive force cells compared with the control groups. This suggests that optimal compressive force promoted osteoclast differentiation and fusion.

Subsequent to the release from optimal compressive force, the number of TRAP-positive multinucleated osteoclasts were counted. The number of osteoclasts in the control group was increased compared with the cells that were released from compressive force. This suggests that release from optimal compression suppresses osteoclast differentiation. Thus, how the expression of osteoclast differentiation genes was altered by release from compressive force was subsequently investigated using RT-qPCR analysis.

NFATc1 mRNA levels in the control groups were increased at $0,1,3$ and $6 \mathrm{~h}$ compared with cells that were release from compressive force. Thus, NFATc1 mRNA expression was inhibited for $6 \mathrm{~h}$ subsequent to release from compressive force. NFATc1 is the master switch for osteoclast differentiation (28). The increasing of expression of NFATc1 lead to expression of other osteoclast-specific genes increased in the control group. TRAP, RANK, MMP-9, Cath-K, ClC7, ATP6i, DC-STAMP and OC-STAMP mRNA levels peaked at $3 \mathrm{~h}$ in the control groups and were significantly increased compared with the cells released from compressive force. Although the NFATc1 mRNA level in the control group was higher than the compressive force group at $0 \mathrm{~h}$, these data were consistent with the results of Hayakawa et al (10) and it was noted that compressive force affected the expression of NFATc1 at $0 \mathrm{~h}$. However, release from compressive force also affected the expression of NFATc1 at 1, 3 and $6 \mathrm{~h}$.

The inhibition of the expression levels of TRAP, RANK, MMP-9, Cath-K, ClC7, ATP6i, DC-STAMP and OC-STAMP mRNA peaked at $3 \mathrm{~h}$ after release from compressive force. TRAP and RANK are histochemical markers of osteoclasts (29). Inhibition of TRAP and RANK expression indicates a reduction in the number of osteoclasts. MMP-9 expression is essential for the migration of osteoclasts through collagen in the periosteum and developing marrow cavity of primitive long bones $(30,31)$. Bone resorption may be significantly reduced by inhibition of MMP-9 (32,33).

Cath-K, ClC7 and ATP6i directly affect bone resorption within the ruffled border of osteoclasts (34-36). This expression is associated with bone resorption and was inhibited following the release from compressive force. In addition to inhibition of MMP-9 mRNA expression, osteoclast migration and resorption may be decreased.

DC-STAMP and OC-STAMP modulate cell-cell fusion in osteoclasts, and are induced by the RANKL-NFATc1 axis (37). Decreased expression of DC-STAMP and OC-STAMP inhibit the fusion of osteoclasts. Thus, the number of large osteoclasts was decreased. The current study demonstrated that optimal compressive force promoted osteoclast differentiation and fusion; however, release from this compressive force suppressed osteoclast differentiation and fusion.

The major causes of orthodontic relapse are considered to be gingival fibers and unbalanced lip-tongue force. We hypothesize that the suppression of osteoclast differentiation and fusion following release from optimal compressive force also has a role in orthodontic relapse. Release from compressive force suppresses osteoclast differentiation, accelerating bone formation, whereas, release from tensile force promotes osteoclast differentiation, accelerating bone resorption (8).

This mechanism may be a factor involved in orthodontic relapse, however, further research is necessary to clarify the mechanism of the relapse following active orthodontic treatment.

\section{Acknowledgements}

We are grateful to Dr K. Shibata (Department of Orthodontics Dentistry, Hokkaido University Graduate School of Dental Medicine, Sapporo, Japan) for technical advice and support. This study was supported in part by the Japan Society for the Promotion of Science Grant-in-Aid for Scientific Research (grant nos. 25463161, 24659906 and 24593071) and for Young Scientists (grant no. 2586199403).

\section{References}

1. Karsenty G and Wagner EF: Reaching a genetic and molecular understanding of skeletal development. Dev Cell 2: 389-406, 2002.

2. Teitelbaum SL and Ross FP: Genetic regulation of osteoclast development and function. Nat Rev Genet 4: 638-649, 2003.

3. Roberts-Harry D and Sandy J: Orthodontics. Part 11: Orthodontic tooth movement. Br Dent J 196: 391-394, 2004.

4. Bourauel C, Vollmer D and Jäger A: Application of bone remodeling theories in the simulation of orthodontic tooth movements. J Orofac Orthop 61: 266-279, 2000 (In English, German).

5. Boyle WJ, Simonet WS and Lacey DL: Osteoclast differentiation and activation. Nature 423: 337-342, 2003.

6. Takayanagi H: The role of NFAT in osteoclast formation. Ann N Y Acad Sci 1116: 227-237, 2007.

7. Zhang F, Wang CL, Koyama Y, Mitsui N, Shionome C, Sanuki R, Suzuki N, Mayahara K, Shimizu N and Maeno M: Compressive force stimulates the gene expression of IL-17s and their receptor in MC3T3-E1 cells. Connect Tissue Res 51: 359-369, 2010.

8. Shibata K, Yoshimura Y, Kikuiri T, Hasegawa T, Taniguchi Y, Deyama Y, Suzuki K and Iida J: Effect of the release from mechanical stress on osteoclastogenesis in RAW264.7 cells. Int J Mol Med 28: 73-79, 2011.

9. Kameyama S, Yoshimura Y, Kameyama T, Kikuiri T, Matsuno M, Deyama Y, Suzuki K and Iida J: Short-term mechanical stress inhibits osteoclastogenesis via suppression of DC-STAMP in RAW264.7 cells. Int J Mol Med 31: 292-298, 2013.

10. Hayakawa T, Yoshimura Y, Kikuiri T, Matsuno M, Fukushima K, Shibata K, Deyama Y, Suzuki K and Iida J: Optimal compressive force accelerates osteoclastogenesis in RAW264.7 cells. Mol Med Rep 12: 5879-5885, 2015.

11. Suzuki N, Yoshimura Y, Deyama Y, Suzuki K and Kitagawa Y: Mechanical stress directly suppresses osteoclast differentiation in RAW264.7 cells. Int J Mol Med 21: 291-296, 2008.

12. Rubin J, Murphy TC, Fan X, Goldschmidt M and Talor WR: Activation of extracellular signal-regulated kinase is involved in mechanical strain inhibition of RANKL expression in bone stromal cells. J Bone Miner Res 17: 1452-1460, 2002.

13. Koike M, Shimokawa H, Kanno Z, Ohya K and Soma K: Effects of mechanical strain on proliferation and differentiation of bone marrow stromal cell line ST2. J Bone Miner Metab 23: 219-225, 2005.

14. Kanzaki H, Chiba M, Sato A, Miyagawa A, Arai K, Nukatsuka S and Mitani H: Cyclical tensile force on periodontal ligament cells inhibits osteoclastogenesis through OPG induction. J Dent Res 85: 457-462, 2006.

15. Nishijima Y, Yamaguchi M, Kojima T, Aihara N, Nakajima R and Kasai K: Levels of RANKL and OPG in gingival crevicular fluid during orthodontic tooth movement and effect of compression force on release from periodontal ligament cells in vitro. Orthod Cranifac Res 9: 63-70, 2006. 
16. Ichimiya H, Takahashi T, Ariyoshi W, Takano H, Matayoshi T and Nishihara T: Compressive mechanical stress promotes osteoclast formation through RANKL expression on synovial cells. Oral Surg Oral Med Oral Pathol Oral Radiol Endod 103: 334-341, 2007.

17. Liu J, Zhao Z, Zou L, Li J, Wang F, Li X, Zhang J, Liu Y, Chen S, Zhi M and Wang J: Pressure-loaded MSCs during early osteodifferentiation promote osteoclastogenesis by increase of RANKL/OPG ratio. Ann Biomed Eng 37: 794-802, 2009.

18. Rubin J, Biskobing D, Fan X, Rubin C, McLeod K and Taylor WR Pressure regulates osteoclast formation and MCSF expression in marrow culture. J Cell Physiol 170: 81-87, 1997.

19. Mehrotra M, Saegusa M, Wadhwa S, Voznesensky O, Peterson D and Pilbeam C: Fluid flow induceds RANKL expression in primary murine calvarial osteoblasts. J Cell Biochem 98 1271-1283, 2006.

20. Tan SD, Vries TJ, Kujipers-Jagtman AM, Semeins CM, Everts V and Klein-Nulend J: Osteocytes subjected to fluid flow inhibits osteoclast formation and formation and bone resorption. Bone 41 : 745-751, 2007.

21. Qing Hong Z, Meng Tao L, Yi Z, Wei L, Ju Xiang S and Li L: The effect of rotative stress on CAII, FAS, FASL, OSCAR, and TRAP gene expression in osteoclasts. J Cell Biochem 114: 388-397, 2013.

22. Makihira S, Kawahara Y, Yuge L, Mine Y and Nikawa H: Impact of the microgravity environment in a 3-dimentional clinostat on osteoblast- and osteoclast-like cells. Cell Biol Int 32: 1176-1181, 2008.

23. Kadow-Romacker A, Haffman JE, Duga G, Wildemann B and Schmidmaier G: Effect of mechanical stimulation on osteoblastand osteoclast-like cells in vitro. Cell Tissues Organs 190: 61-68, 2009.

24. Takeyama S, Yoshimura Y, Deyama Y, Sugawara Y, Fukuda H and Matsumoto A: Phosphate decreases osteoclastogenesis in coculture of osteoblast and bone marrow. Biochem Biophys Res Commum 282: 798-802, 2001

25. Nakamura K, Deyama Y, Yoshimura Y, Suzuki K and Morita M: Toll-like receptor 3 ligand-induced antiviral response in mouse osteoblastic cells. Int J Mol Med 19: 771-775, 2007.

26. Livak KJ and Schmittgen TD: Analysis of relative gene expression data using real-time quantitative PCR and the 2(-Delta Delta C(T)) Method. Methods 25: 402-408, 2001.
27. Reitan K: Tissue behavior during orthodontic tooth movement. Am J Orthod 46: 881-900, 1960.

28. Zhao Q, Wang X, Liu Y, He A and Jia R: NFATc1: Functions in osteoclasts. Int J Biochem Cell Biol 42: 576-579, 2010.

29. Nakagawa N, Kinosaki M, Yamaguchi K, Shima N, Yasuda H, Yano K, Morinaga T and Higashio K: RANK is essential signaling receptor for osteoclast differentiation factor in osteoclastogenesis. Biochem Biophys Res Commun 253: 395-400, 1998.

30. Blavier L and Delaissé JM: Matrix metalloproteinases are obligatory for the migration of preosteoclasts to the developing marrow cavity of primitive long bones. J Cell Sci 108: 3649-3659, 1995.

31. Sato T, Foged NT and Delaissé JM: The migration of purified osteoclasts through collagen is inhibited by matrix metalloproteinase inhibitors. J Bone Miner Res 13: 59-66, 1998.

32. Hill PA, Murphy G, Docherty AJ, Hembry RM, Millican TA, Reynolds JJ and Meikle MC: The effects of selective inhibitors of matrix metalloproteinase (MMPs) on bone resorption and the identification of MMPs and TIMP-1 in isolated osteoclasts. J Cell Sci 107: 3055-3064, 1994.

33. Spessotto P, Rossi FM, Degan M, Di Francia R, Perris R, Colombatti A and Gattei V: Hyaluronan-CD44 interaction hampers migration of osteoclast-like cells by down-regulation MMP-9. J Cell Biol 158: 1133-1144, 2002.

34. Saftig P, Hunziker E, Wehmeyer O, Jones S, Boyde A, Rommerskirch W, Moritz JD, Schu P and von Figura V: Impaired osteoclastic bone resorption leads to osteopeterosis in cathepsin-K-deficient mice. Proc Natl Acad Sci USA 95: 13453-13458, 1998.

35. Kornak U, Kasper D, Bösl MR, Kaiser E, Schweizer M, Schulz A, Friedrich W, Delling G and Jentsch TJ: Loss of the ClC-7 chloride channel leads to osteopetrosis in mice and man. Cell 104: 205-215, 2001

36. Li YP, Chen W, Liang Y, Li E and Stashenko P: Atp6i-deficient mice exhibit severe osteopetrosis due to loss of osteoclast-mediated extracellular acidfiction. Nat Genet 23: 447-451, 1999.

37. Miyamoto H, Suzuki T, Miyauchi Y, Iwasaki R, Kobayashi T, Sato Y, Miyamoto K, Hoshi H, Hashimoto K, Yoshida S, et al: Osteiclasts stimulatory transmembrane protein and dendritic cell-specific transmembrane protein cooperatively modulate cell-cell fusion to form osteoclasts and foreign body giant cells J Bone Miner Res 27: 1289-1297, 2012. 